\title{
Francesco De Cristofaro, Gli ossi di Cuvier
}

\section{Marco Stupazzoni}

\section{Q OpenEdition}

\section{Journals}

\section{Edizione digitale}

URL: https://journals.openedition.org/studifrancesi/40927

DOI: 10.4000/studifrancesi.40927

ISSN: 2421-5856

\section{Editore}

Rosenberg \& Sellier

\section{Edizione cartacea}

Data di pubblicazione: 1 juillet 2004

Paginazione: 209-210

ISSN: 0039-2944

\section{Notizia bibliografica digitale}

Marco Stupazzoni, «Francesco De Cristofaro, Gli ossi di Cuvier», Studi Francesi [Online], 142 (XLVIII | I) | 2004, online dal 30 novembre 2015, consultato il 09 septembre 2021. URL: http://

journals.openedition.org/studifrancesi/40927 ; DOI: https://doi.org/10.4000/studifrancesi.40927

\section{Questo documento è stato generato automaticamente il 9 septembre 2021.}

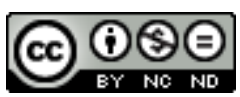

Studi Francesi è distribuita con Licenza Creative Commons Attribuzione - Non commerciale - Non opere derivate 4.0 Internazionale. 


\title{
Francesco De Cristofaro, Gli ossi di Cuvier
}

\author{
Marco Stupazzoni
}

\section{NOTIZIA}

FRANCESCO De CRISTOFARO, Gli ossi di Cuvier, in Zoo di romanzi. Balzac, Manzoni, Dickens e altri bestiari, Napoli, Liguori, 2002 («L'armonia del mondo», 2), pp. 27-96.

1 Mai come nell'Ottocento, il secolo del romanzo per eccellenza, si assiste in maniera così diffusa alla simbiosi tra letteratura e arti figurative nella trattazione dell'elemento zoomorfico, da cui si riflette un sistema aperto e dinamico di modelli del sapere.

2 Da questo punto di vista, puntualizza bene Felice de Cristofaro nel Prologo di questo suo originale e suggestivo volume, il bestiario dell'Ottocento è «una questione, essenzialmente di storia delle idee, che abita una 'stanza della memoria' culturalmente composita» (p. 9) in cui trovano spazio categorie estetiche quali il comico, il brutto e il grottesco, o paradigmi cognitivi come, ad esempio, nel caso specifico di Balzac, le teorie e le collezioni fisionomiche di Gall e di Lavater.

3 Nell'Avant-propos alla Comédie humaine, Balzac afferma esplicitamente che la società sua contemporanea può essere letta e rappresentata come un grande zoo, stabilendo, in questo senso, un sostanziale isomorfismo tra uomo e animale. Tuttavia, si chiede legittimamente l'A., «quanto è rispettata, quanto si diffonde dentro le pratiche concrete del romanziere quella correlazione programmatica?» (p. 28).

4 In questo studio (ma è doveroso menzionare, per la ricchezza dei riferimenti balzachiani, anche l'appendice intitolata Manuale di zoologia realista con cui si chiude il volume), De Cristofaro ricostruisce e interpreta il complesso e variegato mosaico delle specie zoologiche della Comédie, subito assimilate ad altrettante varietà socioantropologiche e, di fatto, adoperate «in quella scrittura 'infinibile' come risorse tematiche e soprattutto metaforiche della mimesis» (Ibid.). Se nel racconto Une passion dans le désert, Balzac «mette a segno /.../ alcune metafore zoomorfe di un'esattezza 
straordinaria» (p. 35) conferendo all'animale «la parvenza d'una donna del demimonde» (p. 34), ne La Fille aux yeux d'or la caratterizzazione animalesca dei personaggi investiti di una funzione narrativa fanno del testo balzachiano «il paradigma perfetto di quella particolare declinazione metaforica dello zoomorfismo» (p. 41) che assume lo statuto di «codice, di metalinguaggio, invadendo in modo indiscriminato lo spazio delle relazioni fra i personaggi» (p. 44).

Lo studio mirato di numerose altre opere della Comédie consente all'A. di produrre una 'tassonomia ragionata' dell'immaginario zoomorfo balzachiano e di individuare, nella prosopopea e nella prosonografia, gli automodelli e gli assi portanti dello zoomorfismo messo in opera dallo scrittore. 